REVISIÓN DE LITERATURA

\title{
ALMIDÓN RESISTENTE EN LA NUTRICIÓN DE ANIMALES MONOGÁSTRICOS I: CONCEPTO, CLASIFICACIÓN Y FUENTES
}

Ericka Salazar-Acosta ${ }^{1 凶}$

\section{RESUMEN}

El almidón resistente (AR) se define como la suma del almidón y productos de la degradación del mismo que no son absorbidos en el intestino, y es uno de los principales sustratos de fermentación que se encuentran en el colon. Existen cuatro tipos de AR: el tipo I, almidón físicamente inaccesible en la matriz del alimento; el tipo II, almidón que en su estado nativo se encuentra en forma de gránulos en el interior de la célula vegetal, tiene un alto contenido de amilosa; el tipo III, también conocido como almidón retrogradado y el tipo IV, almidón artificial modificado químicamente. La determinación analítica para comprobar AR en el laboratorio consiste en el método in vitro enzimático Holm para almidón total y Goñi para almidón resistente, además de otro propuesto por la AOAC donde se sustituyen productos colorimétricos por curvas alcanzadas mediante HPLC. El AR es considerado una fibra dietética, estando presente en granos, leguminosas, tubérculos y frutas, principalmente en musáceas, teniendo una presencia del 15 al $50 \%$, en base seca, de acuerdo a la variedad estudiada. El objetivo de esta revisión es caracterizar el término de almidón resistente y ejemplificarlo en materias primas de uso tradicional y no tradicional para alimentación animal, principalmente para animales monogástricos.

Palabras clave: almidón resistente, carbohidratos, monogástricos, fibra dietética, nutrición animal.

\footnotetext{
${ }^{1}$ Universidad de Costa Rica, Centro de Investigación en Nutrición Animal. San José, Costa Rica. $\triangle$ Autora para correspondencia: erickasal2801@gmail.com 


\section{ABSTRACT}

Resistant starch in the nutrition of monogastric animals: concept, classification and sources. Resistant starch (RS) is defined as the sum of starch and its degradation products that are not absorbed in the small intestine of healthy individuals, and is one of the main fermentation substrates found in the colon. There are four types of RS: type I, physically inaccessible starch in the food matrix; type II, starch that in its native state is in the form of granules inside the plant cell, with high content of amylose; type III, also known as retrograded starch and type IV, chemically modified starch. The analytical determination to check RS in the laboratory consists of the enzymatic in vitro method Holm for total and Goñi for resistant starch, in addition to another method proposed by the AOAC where colorimetric products are replaced by curves reached by HPLC. The RS can be considered a dietary fiber, being present in grain, legumes, tubers and fruits, mainly in musaceas, with an average content of 15 to $50 \%$, on dry basis, according to the variety studied. The objective of this review is to characterize the term resistant starch, making it more popular among the population and exemplifying it in raw materials of traditional and non-traditional use for animal feed, mainly for monogastric animals.

Key words: resistant starch, carbohydrates, monogastric, dietary fiber, animal nutrition. 


\section{INTRODUCCIÓN}

La alimentación de animales monogástricos en el trópico se ha basado tradicionalmente en el uso de granos, mediante la modalidad de alimento balanceado o concentrado, siendo éste definido como el conjunto de alimentos con alta concentración energética y proteica por unidad de materia seca (Parsi et al., 2001). Las materias primas utilizadas, en su mayoría granos, han sido caracterizados por su contenido nutricional tal como energía metabolizable, proteína cruda, fibra cruda, cenizas, entre otros, sin dar relevancia a otros componentes de la dieta que pudieran tener una función nutracéutica para el animal que lo consuma.

Debido a la ausencia de información de alimentos que proporcionen beneficios en la salud de los animales al ser ingeridos, en los últimos años se ha estandarizado el concepto de calidad de acuerdo a su valor nutricional, a partir de la composición del concentrado y su posterior absorción o asimilación de nutrientes en el organismo del animal al que vaya destinado (Maroto et al., 2011). Dejando de lado otros componentes que en caso de estar presentes en la dieta de los animales podrían mejorar no solo la salud de los mismos sino también su productividad.

Tal es el caso del almidón, del cual generalmente se hace referencia al polisacárido de reserva de las plantas (Bello-Pérez et al., 2006), que para los animales resulta en un carbohidrato de fácil digestión y absorción que se consume en granos, tubérculos y legumbres. En el caso de cerdos y aves, el almidón es la principal fuente de glucosa en la dieta, por lo que conocer sus características y formas, como es el caso del almidón resistente, hacen que se comprenda mejor su composición y digestibilidad (Cowieson, 2016).

El almidón se concibe como una sola porción que actúa como fuente de energía en monogástricos y como alimento para la flora ruminal en rumiantes, sin embargo, el almidón está conformado por una fracción lineal de amilosa y una ramificada de amilopectina, ambos constituidos por cadenas de D-Glucosa (Bello-Pérez et al., 2006), que al analizarse de manera independiente, pueden aportar mucho más que sólo energía a quien lo consume. Tal es el caso del almidón resistente, el cual consiste en la suma del almidón y productos de la degradación del almidón que no son absorbidos en el intestino delgado de 
individuos saludables, y es uno de los principales sustratos de fermentación que se encuentran en el colon, además de ser una buena fuente de butirato en la dieta de monogástricos (Nils, 1997).

La resistencia del almidón también se mide en los vínculos generados en la matriz de granos, tal es el caso del maíz, donde dependiendo de su genética y modo de crecimiento, existe una unión almidón-proteína que según la estrechez presentada entre ellos, se considera vítreo y poco digestible, o harinoso y de fácil digestión (Cowieson, 2016). Por este motivo, así como diversos vínculos con lípidos que dificultan también la digestión simple del almidón, es que se consideran valores variables de almidón resistente según la fuente, confirmando que al contrario de considerarse este polisacárido como homogéneo, es heterogéneamente complejo y dependiente de sus relaciones con proteínas, lípidos e incluso hemicelulosa (Escarpa y González 1997, Cowieson 2016).

La importancia de conocer la función del almidón resistente, reside en sus características como prebiótico (Fuentes-Zaragoza et al., 2011), las cuáles expresan sus beneficios al aumentar el consumo del mismo, generando mayor inmunidad en la microbiota y un aumento en la producción de ácidos grasos volátiles, principalmente butirato, en el colon.

Esta revisión tiene como objetivo caracterizar el término de almidón resistente, y ejemplificarlo en materias primas de uso tradicional y no tradicional para alimentación animal, principalmente para animales monogástricos.

\section{Almidón Resistente}

\section{Tipos de Almidón Resistente}

El almidón resistente es una fracción heterogénea clasificada en cuatro tipos, en función de su estructura fisicoquímica y vinculada con la mayor susceptibilidad al ataque enzimático.

Se define como la suma del almidón y productos de la degradación del mismo que no son absorbidos en el intestino delgado de individuos saludables, y es uno de los principales sustratos de fermentación que se encuentran en el colon. Las características morfológicas de los almidones de diferentes orígenes y su presencia en los alimentos, varía con el genotipo del vegetal, las prácticas de cultivo, método de producción y crecimiento así como 
el procesamiento del mismo (Bello-Pérez et al 2006; Martínez-Mora 2015). Existen cuatro tipos de AR (Escarpa y González, 1997; Fuentes et al., 2010) que se pueden observar en el Cuadro 1.

Cuadro 1. Tipos de almidón resistente presentes en materias primas para alimentación animal.

\begin{tabular}{cl}
\hline Tipo de AR & \multicolumn{1}{c}{ Descripción } \\
\hline I & Almidón físicamente inaccesible en la matriz del alimento ya que se \\
& encuentra protegido por las paredes celulares vegetales, está presente \\
& en alimentos parcialmente molidos como legumbres, cereales y \\
& semillas. \\
& Almidón que en su estado nativo se encuentra en forma de gránulos en \\
& el interior de la célula vegetal, tiene un alto contenido de amilosa. La \\
II & papa, el plátano y la yuca, entre otros, poseen este tipo de almidón. Si \\
& se utilizan altas temperaturas al cocinarse, se vuelve digestible. \\
& También conocido como almidón retrogradado. Este se forma después \\
& de tratamientos térmicos de calentamiento-enfriamiento con \\
& condiciones de alta humedad y temperatura. Consiste en amilosa \\
& retrógrada de doble hélice, unidas entre sí por puentes de hidrógeno. \\
& Esta estructura es la responsable de la inaccesibilidad de las enzimas \\
& digestivas del tracto gastrointestinal \\
& Almidón artificial modificado químicamente por eterización o \\
& esterificación que no puede ser hidrolizado por las enzimas digestivas \\
& No se encuentra en la naturaleza.
\end{tabular}

Adaptado de Escarpa y González (1997) y Fuentes et al. (2010).

\section{Composición del almidón resistente}

El almidón que se resiste a ser digerido por el intestino delgado, por ende se encuentra sujeto a una fermentación ácido láctica, constituyendo parte de la fibra dietética de animales monogástricos (Nils, 1997), se encuentra formado por amilosa y amilopectina al igual que el almidón total, no obstante, la forma que adquieren dichas partículas, varía según el tipo de almidón resistente encontrado. 
La amilosa es un polímero lineal, y sus asociaciones corresponden a cadenas de puentes de hidrógeno; por el contrario, la amilopectina es un polímero ramificado, y su asociación se da por cadenas cortas de su ramificación (Escarpa y González, 1997). Según (Nils, 1997), la amilosa consiste en 1,4- $\alpha$-D-anhidroglucosa en forma de hélice, con una superficie hidrofílica pero con un núcleo hidrofóbico, mientras la amilopectina está formada por 1,6-aanhidroglucosa agrupada en cadenas cortas de más fácil acceso.

El contenido de amilosa es importante para la producción de AR, ya que los almidones con un alto contenido de este polímero tienen mayor capacidad de retrogradación, y por tanto, mayor formación de AR (Bello-Pérez et al., 2006), además las hélices de la amilosa, forman cristales que convierten el almidón en una partícula moderadamente indigestible por las enzimas digestivas de animales monogástricos (Cowieson, 2016). En cuanto a la molécula de amilopectina, esta tiene cadenas más largas, por tanto, después de un tratamiento térmico su reorganización es más lenta y hay menor formación de AR (Bello-Pérez et al., 2006). No obstante, Gallant et al. (1997), indican que la amilopectina puede tener una forma cristalina o amorfa, lo cual transformaría la estructura y organización de los granos de almidón, logrando cambios significativos en la resistencia de éste al ataque enzimático.

La evaluación de ambos componentes de este polisacárido es indispensable para poder estimar el valor aproximado de AR que tendrá el alimento o materia prima que se vaya a utilizar, y es que a partir de la composición del grano, si este es más alto en amilosa o amilopectina, así corresponderá su nivel de digestibilidad, y por tanto podría decirse si corresponde o no a una materia prima con mayor contenido de almidón resistente, (Cowieson, 2016). En el caso de materias primas con alto valor de amilosa, que además sufrieron un tratamiento térmico calor-enfriamiento muy abrupto, el contenido de almidón resistente tipo III tendrá mayor probabilidad de estar presente, debido a la gelatinización y posterior retrogradación de la a-amilosa, dando como consecuencia la presencia de una fracción cristalina que será inaccesible por enzimas digestivas, principalmente amilasa pancreática (Escarpa y González, 1997).

Cowieson (2016), y Escarpa y González (1997), indican en diversos estudios, que el contenido de lípidos y proteínas pueden variar el contenido y composición del AR encontrado en distintas materias primas.

- Lípidos: se consideran componentes minoritarios en el almidón, sin embargo, influyen en los procesos de gelatinización y retrogradación. Existen dos vías de 
inclusión de lípidos en las matrices de amilosa: de manera superficial o intragranular; ambas vías reducen el nivel y la calidad de almidón resistente en la materia prima, permitiendo que las enzimas tengan mayor acceso a la amilosa, además de que impide la retrogradación ya que la unión almidón-lípido por sí sola forma una doble hélice que compite por la formación de la doble hélice de la retrogradación, afectando el proceso de cristalización que vendría a formar el almidón resistente. Los lípidos involucrados serían los inherentes a cada materia prima (endógenos), principalmente aceites o ácidos grados insaturados pertenecientes al grano que se analice.

- Proteínas: en el caso de granos con alta dureza en su corteza (como el sorgo), el almidón suele almacenarse en la pared celular del grano, específicamente en la estructura proteica. Por tal motivo, la presencia de dos tipos de almidón resistente: I y III, va a variar de acuerdo al procesamiento y tipo de matriz proteica, en caso de ser abierta o cerrada. El tipo I se encontraría en mayor cantidad, en materias primas donde la unión almidón-proteína (enlace peptídico) sea muy estrecha, lo que sería indigestible por enzimas digestivas; el tipo III estaría presente en materias procesadas y con menos rigidez proteica, donde la amilosa pueda gelatinizarse y por ende llegar a la retrogradación.

\section{Materias primas que contienen almidón resistente}

El almidón resistente se encuentra de forma natural en frutas, leguminosas y tubérculos (Jiménez et al., 2001). En su mayoría, las materias primas que son utilizados como fuente de almidón en alimentación animal poseen mayor concentración de éste en estadíos inmaduros, debido a que durante el proceso de maduración de la fruta, la concentración de azúcares simples tiene mayor porcentaje que la concentración de polisacáridos (BelloPérez et al., 2006). A continuación, se describen las principales fuentes de AR en materias primas para alimentación animal. 


\section{Musáceas}

La harina y el almidón proveniente de musáceas son fuente de almidón resistente, lo que permite establecer que el consumo de los mismos o de alimentos elaborados a partir de estos sean beneficiosos para la salud entérica (Pérez y Marín, 2009). El contenido de almidón en pulpa de banano, se encuentra entre 10 y $80 \%$ del contenido de materia seca, de acuerdo a la variedad estudiada, al grado de maduración de la fruta y al método de extracción (Pérez y Marín, 2009), en el caso del plátano (Musa sp), corresponde a un 70\% del contenido de MS (Bello-Pérez et al., 2006).

Jiménez et al. (2011), indican que el plátano cuadrado es una fuente importante de almidón, ya que entre el 70 y $80 \%$ del fruto es almidón, del cual el 55\% es almidón resistente, considerándose que dicha musácea es una fuente natural de AR, pues para otras variedades se ha reportado que para obtener concentraciones similares de almidón resistente a las encontradas en este plátano se ha recurrido a la mutación genética, mientras que en éste se encuentra de forma natural.

El plátano verde es considerado el alimento natural, sin cocción, prensa, deshidratación, entre otros procesos, con mayor contenido de AR. Su contenido de almidón resistente varía entre $47 \%$ y $57 \%$; sin embargo cuando se procesa como harina, los valores obtenidos resultan en $73,4 \%$ de contenido total de almidón y un $17,5 \%$ de contenido de AR (Fuentes et al., 2010).

En el caso del banano, el contenido de AR, del total de la materia seca, fue determinado por Martínez-Mora (2015). Los gránulos de almidón nativo de banano muestran ser resistentes a la hidrólisis enzimática, por lo que se ha propuesto que esto está en función de la superficie lisa del gránulo, la presencia de restos de pared celular que pueden atrapar a los gránulos, y el grado y tipo de cristalinidad del mismo (Pérez y Marín, 2009). Los porcentajes de almidón resistente se presentan en el Cuadro 2. 
Cuadro 2. Contenido de almidón resistente, como porcentaje de la materia seca, en cuatro variedades de banano.

\begin{tabular}{lc}
\hline \multicolumn{1}{c}{ Variedad } & Almidón resistente (\%) \\
\hline Filipino & 56,84 \\
Cavendish & 58,67 \\
Orito & 49,33 \\
Valery & 52,81 \\
\hline
\end{tabular}

Adaptado de Martínez-Mora (2015).

\section{Granos, Leguminosas y Tubérculos}

En el caso del frijol, Jiménez et al. (2011), demostraron que posee mayor AR que el maíz, pero menor que en musáceas, con valores promedio de $13 \%$ respecto a la materia seca. De acuerdo con estudios realizados en México, en general las leguminosas poseen alrededor de un $20 \%$ de AR como porcentaje de la materia seca, siendo este valor alto al compararlo con granos que rondan del 1 al 3\%, como es el caso del maíz (Jiménez et al., 2011).

El tratamiento calentamiento-enfriamiento de almidones comerciales en autoclave, ha podido generar mayores niveles de $A R$ en el caso del almidón de maíz con alto contenido de amilosa. (Bello-Pérez et al., 2006), por lo que podría ser una iniciativa para obtener mayor porcentaje del mismo de alimentos que naturalmente no lo posean o bien empleando hidrólisis ácida parcial, donde Jiménez et al. (2011), citan la posibilidad de aumentar la cantidad de almidón resistente en tubérculos, como el camote, en un rango de 5,4- 22,7\% del total de la materia seca. Fuentes et al. (2010), reportaron valores de AR en papa que alcanzan el 75\%, del almidón total, principalmente del tipo II, pues los tubérculos suelen presentar cristalización en sus gránulos de almidón.

\section{Frutas}

El mango (Manguifera indica L.) en su estado verde o inmaduro, posee almidón que constituye la fracción mayoritaria, 30-50\%, de su base seca (Bello-Pérez et al., 2006). Sin embargo, cuando se trata de AR, el mango presenta valores de $2,7 \%$ de su base seca, lo cual se considera muy bajo a pesar de su alto contenido de amilosa (Jiménez et al., 2011), 
lo cual está relacionado con la presencia de AR tipo III o almidón retrogradado que se forma después de un tratamiento térmico (Ver Cuadro 1), (Escarpa y González, 1997).

En el Cuadro 3 se indican los valores de AR encontrados por Trujillo (2011) en frutas tale como papaya, piña, pera, naranja y manzana. A pesar de ser frutas utilizadas principalmente para consumo humano, permiten conocer y relacionar la información obtenido con otros materiales utilizados para alimentación animal.

Cuadro 3. Contenido de AR del total de materia seca en frutas.

\begin{tabular}{lc}
\hline \multicolumn{1}{c}{ Fruta } & Almidón Resistente $(\%)$ \\
\hline Papaya & 3,11 \\
Piña & 0,46 \\
Pera & 0,73 \\
Naranja & 2,38 \\
Manzana & 0,64
\end{tabular}

Adaptado de Trujillo (2011).

Cabe destacar que en el caso de las frutas, estas tienen dos limitantes a la hora de considerarse su contenido de almidón resistente:

1) Se consumen, en su mayoría maduras, por lo que Fuentes et al. (2010), indicaron que, al madurarse, las frutas y vegetales aumentan su contenido de azúcares simples, reduciendo el porcentaje presente de polisacáridos. Trujillo (2011), indica que la maduración genera una degradación del almidón en glucosa, lo que disminuye el valor cuantificable de almidón total y resistente en frutas maduras.

2) Debido a la condición de madurez, los almidones de frutas poseen un $50 \%$ de almidón digestible (Martínez-Mora, 2015), lo que los convierte en una fuente poco suculenta en AR debido a la presencia de gránulos capaces de absorber agua, sin llegar a gelatinizar e incrementar así su susceptibilidad al ataque enzimático. 


\section{Almidón resistente y concepto de fibra dietética}

La fibra dietética se define como una fracción heterogénea en la que se integran compuestos diferentes, con estructura química y propiedades físicas y biológicas diversas, ejerciendo efectos saludables en el consumidor habitual al no poder ser digerido por las enzimas digestivas endógenas (Sastre, 2003). Se dice que no es una entidad completa, sino un término colectivo para mezclas complejas de materiales con distintas propiedades químicas y físicas, polímeros de carbohidratos que no son digeridos ni absorbidos en el intestino delgado (Fuentes et al., 2010).

La presencia de fibra dietética está representada fundamentalmente por celulosa, hemicelulosa, sustancias pécticas y lignina, así como otros polisacáridos insolubles que se integren a la fibra (Sastre, 2003). El almidón resistente (AR) puede ser considerado fibra dietética debido a su acción sobrepasante; razón por la cual en la actualidad se aisla de distintos alimentos con la finalidad de buscar almidones con propiedades funcionales no convencionales. (Bello-Pérez et al., 2006).

El almidón ingerido en la dieta que escapa a la hidrólisis de las enzimas digestivas oscila en un rango del 1 al 20\%, dependiendo de la forma ingerida, de la fuente originaria del almidón y de la metodología seguida para detectarlo (Sastre, 2003), por eso se conoce como almidón resistente, ya que se resiste a la digestión enzimática intestinal.

Según Fuentes et al. (2010), el almidón resistente es considerado un tipo de fibra dietética con ventajas sobre otras, por lo que se relaciona mejor con el término de "alimentos funcionales", ya que tiene propiedades de gelatinización, viscosidad y absorción de agua, sin cambiar sensorialmente los alimentos que lo poseen.

\section{Determinación analítica y nuevas metodologías relacionadas al almidón resistente}

Entre las metodologías más utilizadas para determinar AR en el laboratorio, se encuentra el método in vitro enzimático: Holm para almidón total (Holm et al., 1985) y Goñi I para almidón resistente (Goñi et al., 1996). El método Goñi I (Goñi et al., 1996), consiste en una hidrólisis proteica con pepsina a $\mathrm{pH}$ ácido para simular condiciones estomacales y una hidrólisis de almidón digestible con a-amilasa pancreática porcina por 16 horas. Al centrifugar, el residuo de almidón indigestible se dispersa en medio alcalino e hidroliza en su totalidad con amiloglucosidasa de Aspergillus niger determinándose la glucosa liberada 
con un reactivo de glucosaoxidasa/peroxidasa y determinándose el nivel de almidón por espectrofotometría (Soto, 2010).

Además de este método, se utiliza otro procedimiento donde se reemplaza el uso de enzimas adicionales donde sea requerida la espectrofotometría, con el fin de realizar las mediciones finales en cromatografía líquida de alta eficacia o HPLC por sus siglas en inglés (High Performance Liquid Chromatography). También se trata de un método enzimático pero varían los reactivos utilizados (AOAC, 2005).

Bello-Pérez et al. (2006), cita un método para obtener AR, el cual involucra la gelatinización de un almidón (con más de 40\% de amilosa), desramificación enzimática, inactivación de la enzima y separación del producto por secado, extrusión o cristalización. También se ha podido desarrollar un método de determinación y creación de material alto en almidón resistente retrógrado por medio de autoclaves con altas temperaturas, tal es el caso del AR determinado por Escarpa y González (1997), donde explican que el almidón resistente tipo III se forma a partir de los gránulos nativos del almidón después de su gelatinización y retrogradación alcanzados en autoclave.

Durante el proceso de gelatinización, en presencia de agua y por encima de una temperatura característica de cada almidón, se destruye el orden del almidón, rompiéndose los puentes de hidrógeno entre las cadenas de amilosa y perdiendo la cristalinidad del mismo. Posteriormente, el granulo absorbe agua y se produce un hinchamiento, seguido de una dispersión de las cadenas del polímero, donde principalmente es la amilosa la que se difunde al exterior, quedando una matriz de gránulos con un esqueleto de amilopectina (Colonna et al., 1992) y por lo tanto la fracción de amilosa reestructurada consecuente, da lugar a la amilosa retrógrada que sería el almidón resistente tipo III. Los rendimientos reportados en papa por Escarpa y González (1997), indican que con un 40\% de amilosa, se puede alcanzar hasta un $20 \%$ de $A R$, de su base seca.

Cada método posee sus ventajas y desventajas, así como su adaptación determinada por el laboratorio donde se realice. Para ejemplificar de mejor manera los puntos a considerar para la selección de metodologías, se explica cada punto en el Cuadro 4. 
Cuadro 4. Factores implícitos en las metodologías de determinación de AR.

\begin{tabular}{ll}
\hline \multicolumn{1}{c}{ Metodología } & \multicolumn{1}{c}{ Factores a considerar } \\
\hline AOAC (AOAC, 2005) & Requiere equipo especializado (HPLC). \\
& Personal capacitado en lectura de curvas alcanzadas por \\
& el equipo, calibración, integración e interpolación de \\
& datos. \\
& Los reactivos utilizados son de bajo costo, pero su \\
& dosificación depende del técnico a cargo. \\
& Se sistematiza el trabajo, por lo que se requiere menos \\
& tiempo invertido por el personal de laboratorio. \\
\hline Enzimático & No necesita equipo especializado. \\
colorimétrico & Los reactivos se consiguen dosificados en un "Kit" listo \\
(Goñi et al., 1996) & para ser utilizado. \\
& La adquisición del Kit es económicamente costosa, y \\
& limita la cantidad de muestras a analizar por período de \\
& tiempo. \\
& Personal capacitado en interpolación de datos.
\end{tabular}

\section{CONSIDERACIONES FINALES}

Se logra concluir que el almidón resistente está presente en muchas de las materias primas de uso para alimentación animal, tal es el caso del banano, plátano, guineo, maíz y trigo, entre otras. Los niveles de los mismos aún no han sido evaluados en Costa Rica.

El uso de musáceas, papa, yuca y demás materias primas almidonosas, puede convertirse en un aliado en la nutrición entérica de animales monogástricos, generando mayores contenidos de ácidos grasos volátiles y salud en la microbiota intestinal.

El almidón resistente es una herramienta útil que aún no ha sido trabajada en Costa Rica, y ha venido creciendo a nivel internacional el interés por su uso en nutrición animal. Su posible efecto como fibra y prebiótico, lo vuelven teóricamente relevante y permite iniciar un proceso investigativo que mejore la producción y salud animal en el país. 


\section{LITERATURA CITADA}

AOAC. 2005. AOAC Official method 996.11 Starch (Total) in Cereal Products. Amylogluclucosidase- $\alpha$-amylase method. Metodología de la AACC.

Bello-Pérez L., R. González-Soto, M. Sánchez-Rivero, F. Gutiérrez-Merz, y T. VargasTorres. 2006. Extrusión de almidones de fuentes no convencionales para la producción de almidón resistente. Agrocien. 40: 441-448.

Colonna P., V Leloup, y A. Buleon. 1992. Limiting factors of starch hydrolysis. Eur. J. Clin. Nutrition 4S167-S:32.

Cowieson, A. 2016 Unlocking the potential of dietary starch with exogenous a-amylase. DSM Nutritional Products. Kaiseraugst, Suiza.

Escarpa A., y González M. 1997. Tecnología del almidón resistente. Food Science and Technology International. 3: 149-161.

Fuentes-Zaragoza, E., M. Riquelme-Navarrete, E. Sánchez-Zapata, y J. Pérez-Álvarez. 2010. Resistant starch as a functional ingredient: A review. Food Research International. 43: 931-942.

Fuentes-Zaragoza E., E. Sánchez-Zapata, E. Sendra, E. Sayas, C. Navarro, J. FernándezLópez, y J. Pérez-Álvarez. 2011. Resistant starch as a prebiotic: A review. Starch Journal. 63: 406-415.

Gallant D., B. Bouchet, y P. Baldwin. 1997. Microscopy of starch: evidence of a new level of granule organization. Elsevier. 32: 177-191p.

Goñi I., L. García, E. Mañas, y F. Saura. 1996. Análisis de almidón resistente: un método para alimentos y productos alimenticios. Quím. Alimenticia. 56:445-449.

Holm J.,I. Björk, A. Drew, y N. Asp. 1985. A rapid method for the analysis of starch. Starch. 38:224-229.

Jiménez R., N. González, A. Magaña, y A. Corona. 2011. Contenido de almidón resistente en alimentos consumidos en el sureste de México. UNACAR Tecnociencia. 5(2): 2734. 
Maroto F., A. Gómez, J. Guerrero, A. Garrido, y D. Pérez. 2011. La valoración nutricional de los alimentos para animales: génesis de la información. XXVII Curso de especialización, FEDNA. Madrid, España. pp 51-52.

Martínez-Mora E. 2015. Caracterización morfológica y contenido de almidón resistente y disponible en bananos (Musa sapientum) exportables del Ecuador. Rev. Española de nutrición humana y dietética. 19(3): 153-159.

Nils G. 1997. Resistant Starch- An update on its Physiological Effects. Dietary Fiber in Health and Disease. Series Advances in Experimental Medicine and Biology. 427: 201-210.

Parsi J., L. Godio, R. Miazzo, R. Maffioli, A. Echeverria, y P. Provensal. 2001. Valoración nutritiva de los alimentos y formulación de dietas. Producción animal Argentina. Consultado 13 ag. 2017. Disponible en http://www.produccionanimal.com.ar/informacion_tecnica/manejo_del_alimento/16valoracion_nutritiva_de _los_alimentos.pdf.

Pérez E., y J. Marín. 2009. Situación actual de las harinas de banano: Usos potenciales en la agroindustria nacional. Producción Agropecuaria. 2(1): 65-68.

Sastre, G. 2003. Fibra y prebióticos: conceptos y perspectivas. Gastroenterol Hepatol. 26 (1): 6-12.

Soto, V. 2010. Cuantificación de almidón total y de almidón resistente en harina de plátano verde (Musa cavendishii) y banana verde (Musa paradisíaca). Boliviana de Química. 27(2).

Truijillo, C. 2011. Determinación de la fracción indigerible y fibra dietética en frutas y verduras de mayor consumo en México. Tesis. Maestría. Instituto Politécnico Nacional. Morelos, México. 84p. 